\title{
Novo Títular da Cátedra de Direito Romano Dr. Alexandre Augusto de Castro Correia.
}

O Dr. Alexandre Augusto de Castro Correia, filho do prof. Dr. Alexandre Correia, e de D. Maria Conceição de Castro Correia, nasceu nesta capital a 13 de outubro de 1925.

Fêz o curso primário e os quatro primeiros anos do currículo ginasial no Ginásio Ipiranga desta capital, completando-o no Liceu Franco-Brasileiro, aos 15 anos de idade.

Em 1943 ingressou na Faculdade de Direito da Universidade de São Paulo e logo após na Faculdade de Filosofia de São Bento, recebendo em 1947, ao mesmo tempo, dois títulos universitários: o de bacharel em Ciências Jurídicas e Sociais e o de Licenciado em Filosofia.

Dois anos após, em 1950, apresentando a tese $O$ Estoicismo no Direito Romano, submeteu-se a concurso para livre docência em Direito Romano, tomando posse do cargo a 4 de dezembro dêsse mesmo ano; lecionou desde então essa matéria no curso noturno, o qual fôra recentemente inaugurado.

Em 1952 viajou para a América do Norte a fim de freqüentar o curso de Direito Comparado da "Southern Methodist University" (Dallas, Texas) dos Estados Unidos, obtendo o título de "Master of Laws in Comparative Law".

Retornando ao Brasil foi convidado para lecionar Direito Romano na Faculdade de Direito de Campinas e, em 1957 quando de sua fundação, na Faculdade de Direito de Sorocaba, de cuja Congregação é membro integrante até o presente. 


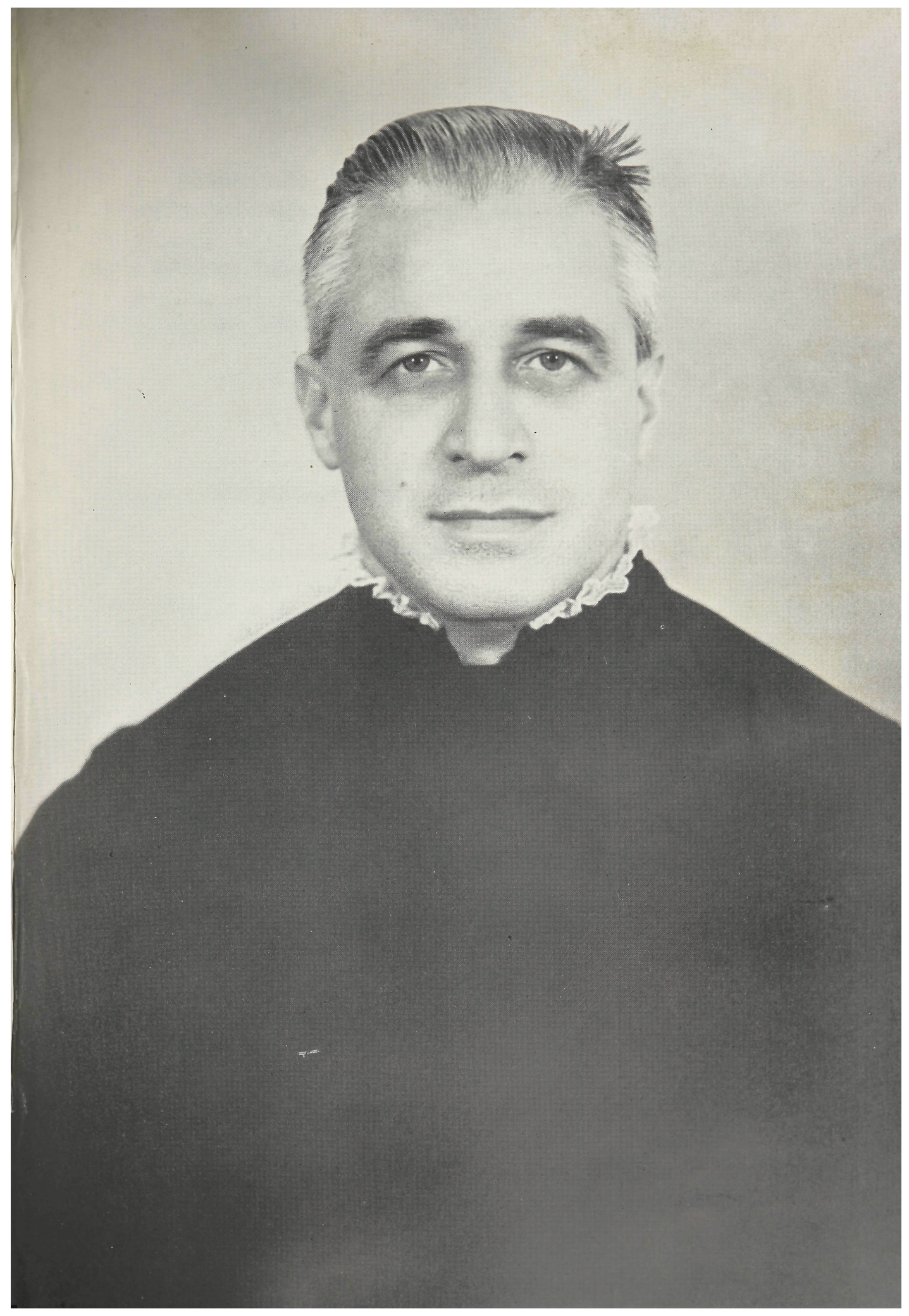


Conhecendo profundamente diversas línguas, francês, inglês, alemão, italiano, latim e grego, o Dr. Alexandre Augusto de Castro Correia, além de publicar vários livros e artigos, elaborou a tradução de obras em italiano, latim e inglês, de clássicos e renomados autores que se tornaram de manuseio constante pelos estudiosos da matéria.

\section{Bibliografia.}

Para o concurso à cátedra, apresentou o novo professor a seguinte bibliografia:

O Estoicismo no Direito Romano (Tese), São Paulo, s.c.p., 1950.

Manual de Direito Romano, 2. ${ }^{\mathrm{a}}$ ed. (Colaborador), São Paulo, Saraiva, 1953-55.

Direito Romano: a Mancipatio, o Nexum e a in Jure Cessio (Tese), São Paulo, Saraiva, 1960.

Estudos de Filosofia no Direito Latinoamericano nos Estados Unidos, in Revista da Faculdade de Direito, Universidade de São Paulo, v.48:97-105, 1953.

$O$ Direito Romano Vivo, in Revista da Faculdade de Direito, Universidade de São Paulo, v. 49: 297-308, 1954.

A Filosofia do Direito Penal nas Confissões de Santo Agostinho, in Revista da Faculdade de Direito, Universidade de São Paulo, v.54 (2) : 171-179, 1959.

As Obrigações Solidárias em Direito Romano, in Revista da Faculdade de Direito, Universidade de São Paulo, v.55: 197-240, 1960.

Traduções:

Gaio (séc. II, d.C.). Institutas (In Correia - Sciascia). Manual de Direito Romano, 2. ${ }^{\mathrm{a}}$ ed., 1953-55, v. 2, p. 71-289. 
Malatesta, Nicola F., A Lógica das Provas em Matéria Criminal, São Paulo, Saraiva, 1960.

Thomas, Ann (Van Wynen), O Comunismo Contra o Direito Internacional, São Paulo, Saraiva, 1958.

\section{Posse da cátedra de Direito Romano.}

Com a tese Direito Romano: a Mancipatio, o Nexum e a in Jure Cessio submeteu-se o Dr. Alexandre Augusto de Castro Correia a concurso de títulos e provas à cátedra de Direito Romano, vaga com a aposentadoria do Prof. Alexandre Correia. Classificado em primeiro lugar por unanimidade, tomou posse da cátedra em sessão solene da Congregação realizada a 5 de fevereiro do corrente ano, presidida pelo Sr. Diretor Prof. Dr. Luís Eulalio de Bueno Vidigal.

Introduzido no recinto foi saudado pelo Prof. Dr. Washington de Barros Monteiro que proferiu vibrante discurso.

\section{Discurso de saudação pronunciado pelo Professor}

Dr. Washington de Barros Monteiro.

Quando em 1927 ingressei nesta Faculdade, para receber grau em 1931, ainda aqui ressoavam as magistrais preleções de direito romano do grande mestre que havia sido Reinaldo Porchat. Tinha êle, realmente, o sublime dom da eloqiïência, que é, no dizer de Eurípedes, a rainha dos corações. A um só tempo, êle reunia a propriedade, a elegância da frase, a limpidez e a acuidade do raciocínio. Movimento, dramaticidade, fôrça de persuasão, isto é, os eternos fatôres da eloqüência, Porchat os possuía no mais alto grau. Como Royer-Collard, nunca dizia uma só pa- 
lavra a mais, tudo quanto falava tinha profunda significação.

Depois, veio Spencer Vampré, de quem fui aluno. Culto, erudito, suave no falar, meigo mesmo, era de fato "um semeador de rosas nesse nosso jardim de pedra", como de modo tão belo se expressou Goffredo da Silva Telles Júnior na homenagem póstuma, que se lhe tributou nesta Casa. Dizem que, na vida, a gente tem oportunidade de encontrar-se apenas com uns quatro homens bons. Pois Vampré seria inquestionàvelmente um dêles, tal a suavidade, que sempre irradiava. Essa a impressão que conservo, no recesso de minha alma, do grande mestre, que há pouco se finou.

Em seguida, Alexandre Corrêa, taciturno, severo, porém, um sábio, que acumulou, em tôda a sua proveitosa existência, ciência infinita, que prodigalizou a mancheias a gerações e gerações de estudantes. Vida consagrada ao estudo, nada lhe retrata melhor a personalidade que esta inocente anedota, que ouvi, certa feita, entre alguns de seus colegas de turma. Visitavam-no êsses colegas e, após alguns instantes, foram despedidos com estas palavras: "agora vão embora, que eu preciso estudar".

No dia de hoje, assume a cátedra, em caráter vitalício, Alexandre Augusto de Castro Correia, um moço calado, de maneiras singelas, de atitudes modestas, e que, no convívio do lar, junto ao seu sapientíssimo pai, soube haurir os conhecimentos, que Ihe abriram as portas desta Faculdade.

A cadeira de direito romano tem sido, portanto, aquiuhoada com uma seqüência de notáveis professôres. Preciso era, efetivamente, que assim acontecesse. $O$ direito romano vem a ser um dos máximos monumentos do engenho humano, o fulcro da civilização jurídica ocidental. De fato, como ensina Arangio-Ruiz, os modernos direitos curopeus podem ser considerados, em grande parte, como derivazioni e addatamenti do direito justiniano. Nos romanos quase sempre nos vemos a nós próprios. Aquêle 
que escuta a linguagem do direito romano verdadeiramente entende a linguagem de tôdas as nações (Bynkerschoek).

Até mesmo aquêles que se mostram sistemáticos adversários do direito romano, como Bravard, se inspiraram fortemente nêle. Declarou Laurent, num momento de mau humor: pouco nos importam, hoje, os textos romanos: c'est de l'histoire.

Mas, tais conceitos hão de ser desprezados. Como asseverou Giorgio Del Vechio, assim como no Oriente o supremo tema da atividade espiritual foi a religião, na Grécia a filosofia, em Roma foi o direito. E Leibniz pôde dizer dos jurisconsultos romanos que seus escritos quase atingiam a precisão das verdades matemáticas.

Por isso mesmo, parafraseando Salleiles, pode-se dizer que fazer um código civil, eliminando o direito romano, equivale a fazer um código brasileiro sem direito brasileiro. Sua forte disciplina, a sabedoria de seu desenvolvimento progressivo e a autoridade que representa, eis os dados que the asseguram sua vitalidade e permanência, através dos séculos, bem como sua influência decisiva na educação jurídica dos povos modernos.

Veja-se, a título de exemplo, o que aconteceu com o nosso Código Civil. Na frase de Abelardo da Cunha Logo, se passarmos em revista os 1807 artigos, verificaremos que mais de quatro quintos dêles, ou sejam, 1445 artigos, são produto da cultura romana, ou diretamente apreendidos nas fontes da organização justiniana, ou indiretamente, nas legislações que ai foram nutrir-se largamente, como aconteceu a Portugal, França, Alemanha e Itália, que fizeram do direito romano o manancial mais abundante e profundo, para mitigar sua sêde de saber.

Justiniano, "manso marido de Teodora, mescla de voluptuoso tirano e teólogo austero", foi realmente um imperador-guerreiro, um imperador-arquiteto e um imperador-legista. De suas inúmeras guerras, nada restou, a não ser a súplica do primeiro de seus generais: um óbulo 
para Belisário. De sua arquitetura, sobraram uns poucos monumentos. Mas suas leis governaram o mundo e ainda hoje formam a base de tôdas as legislações.

Se o direito romano é assim como que o esperanto do mundo jurídico, como se expressa Radbruch, bem se compreende a importância de seu estudo e a significação de que se reveste a cerimônia que hoje assistimos nesta Casa. Do nôtvo professor da cadeira muito esperam seus alunos e colegas. Sua Excelência trará certamente novas contribuições para o progresso da ciência jurídica.

Não lhe faltam, para tanto, as indispensáveis credenciais. Sua dissertação de concurso sôbre a mancipatio, o nexum e a in jure cessio constitui realmente notável trabalho e pelo seu mérito outorgou-lhe esta cátedra.

A esta altura, pertencem apenas ao passado as muitas dissenções que o controvertido concurso suscitou. Reconheceu-lhe o Supremo Tribunal Federal seu inconcusso direito. Roma locuta est. Como disse Pimenta Bueno, se a justiça é uma religião social, o Supremo Tribunal é o grande sacerdote dela, o guardião de sua pureza e de sua igualdade protetora.

Por isso, superados todos os desentendimentos, abrem-se as portas desta Faculdade para receber o nôvo catedrático, designando-me o meu eminente diretor, Professor Luís Eulálio de Bueno Vidigal, para dar-lhe as boas vindas e dizer-lhe dos nossos sentimentos amistosos.

Desincumbindo-me do encargo quero dizer que se Alexandre Augusto de Castro Correia deu provas públicas de seu alto valor, existe ainda outro aspecto de sua personalidade, que aqui há de ser ressaltado. Enquanto se prolongava a sua luta, com tôdas as paixões que levantou, nunca se ouviu de Alexandre Augusto uma só palavra de recriminação contra quem quer que seja; nenhuma censura, nenhum queixume, em todos os momentos, a mais serena compreensão. As manifestações, que lhe foram adversas, êle as recebeu como expressão de liberdade de crítica e 
de julgamento, que a todos sempre reconheceu. Nos episódios que se sucederam ao concurso, jamais hesitou emcomparecer às salas de aula, no cumprimento de seu dever, embora talvez mais cômodo lhe fôsse uma compreensivel ausência. Portou-se assim estòicamente, como os romanos, cuja história estudou e aprendeu.

$\mathrm{Na}$ defesa de seus direitos, porém, revelou-se intransigente e inflexível. Aliás, como afirmou Ihering, a luta pelo direito é, na realidade, a poesia do caráter. Resistir à sua violação é um dever do indivíduo para consigo. mesmo e um dever para com a sociedade. Como disse Coelho Neto, só os fracos, os impotentes quedam-se na resignação. Os enérgicos insurgem-se, lutam, dão combate à vida e vencem. Eis, em poucas palavras, o drama de Alexandre Augusto de Castro Correia, a quem a Faculdade de Direito de São Paulo, por meu intermédio, dá as boas. vindas, desejando-lhe, com efusão d'alma, tôdas as venturas.

Oração do professor dr. Alexandre Augusto de Castro Correia.

Agradecendo as palavras que lhe foram dirigidas, disse. o nôvo professor a seguinte oração:

“Ao assumir agora nesta Faculdade sucedendo a meu pai prof. Alexandre Correia, a Cátedra de Direito Romano, desejo aproveitar a oportunidade para efetuar agradecimentos primeiro e em seguida uma como profissão de fé correspondente ao juramento aqui prestado. Os agradecimentos se dirigem inicialmente a meus queridos pais a quem devo criação e educação, e que tenho a felicidade hoje de ver presentes assistindo a esta solenidade; para êles, a cerimônia de minha investidura no honroso cargo de professor catedrático desta gloriosa escola há de representar sem dúvida a melhor recompensa de seus incansáveis esforços, procurando dar aos filhos uma educação capaz: 
de lhes permitir o desempenho digno de funções úteis à coletividade. Manifesto-lhes, pois neste momento e com -alegria minha gratidão filial.

"Da família, sabêmo-lo é complemento a Escola; e nós, paulistas, falando em Escola sempre e instintivamente, por fôrça, como direi, do atavismo pensamos na "velha e sempre nova" Academia do Largo de S. Francisco fundada pelo primeiro Imperador do Brasil e cenáculo por onde passaram os mais notáveis vultos da história jurídica, política e literária de nossa terra, taís como o insigne Joũo Mendes Júnior preclaro professor e magistrado, o grande Barão do Rio Branco, nosso maior diplomata e o incomparável Ruy, justamente cognominado de Cícero brasileiro. Lembro só êstes três nomes para mostrar através dêles a importância perene da Faculdade contribuindo para a formação de nossos grandes homens.

Meus agradecimentos se dirigem pois, em segundo lugar à nobre escola onde tive a ventura de passar a juventude estudando e convivendo com filhos de terra brasileira nascidos em S. Paulo e em outros estados; foi também decisivo para mim, o exemplo de mestres como Waldemar Ferreira, Soares de Faria, Gabriel de Rezende Filho, Braz Arruda, Siqueira Ferreira, já falecidos e dos quais recebi sempre demonstrações de saber, dignidade e cavalheirismo; lembrando-lhes aqui o nome desejo exprimir a gratidão do discipulo guardando dêles recordação grata e indelével.

Sôbre os professôres vivos continuando a tradição dos falecidos basta, creio, dizer: sem êles, jamais seria eu coisa alguma no mundo jurídico brasileiro e a atenção que porventura mereça minha atividade como professor só pode ser compreendida e explicada à luz de sua ação formadora e educadora. Além do estímulo constante representado pela convivência diuturna com meu pai, como poderia eu aqui exprimir a gratidão pelo quanto devo a todos os mes- 
tres, quer quando estudante quer mais tarde, convivendo e trabalhando com êles? Queiram, pois todos benèvolamente aceitar minha homenagem, tributada com a sinceridade de quem lhes admira o talento e o brilho com o qual representam as culminâncias de nossas letras jurídicas.

Os funcionários da Casa são também neste momento credores da expressão de meus agradecimentos pela maneira afável, eficiente e cordial com que sempre me trataram: todos sabemos quanto a ação das instituições em geral e das escolas em particular depende da qualidade de seu pessoal administrativo; a da de nossa Faculdade é modelar, merecendo aplausos em ocasiões solenes como esta.

Não posso finalmente olvidar a juventude acadêmica, a "cupida legum juventus" de Justiniano, primordial razão de ser da existência de nossa Faculdade, É ela, com efeito futuro da pátria, a destinatária de todo o esfôrço educativo desta instituição. Procurando na medida de minhas escassas fôrças servir a tão sagrada missão de colaborar no preparo dos homens de amanhã para o desempenho digno das tarefas de bons cidadãos tenho com certeza, ficado muito abaixo da altura do encargo. Saibam entretanto os senhores estudantes: no decurso de minha atividade nesta nobre Casa tenho envidado sinceros esforços inclusive pela convivência com os mestres, visando desempenhar satisfatòriamente os deveres de professor de direito. Ensinar é arte, cujo aprendizado se aperfeiçoa através de tôda a existência: "Ars longa vita brevis" disse lapidarmente o poeta latino. $\mathrm{O}$ aprendizado pois do professor a fiz em boa parte através do contacto com os alunos; e neste sentido se muito aprendi com meus discípulos espero não ter jamais aprendido à custa dêles, em detrimento e prejuízo de sua formação intelectual. Cumpre-me de qualquer modo declarar neste momento aos jovens: procurarei de boa fé esforçar-me sempre mais para fazer da Cátedra de Direito Romano uma sede da qual se irradie constantemente e com profusão cada vez maior aquela sabedoria imperecível dos 
antigos que atravessou as idades e continua a nutrir as inteligências voltadas para o conhecimento e a prática da Justiça!

"Com o favor de Deus e o auxílio de meus doutos colegas espero contribuir eficazmente para a formação duma plêiade de jovens romanistas capazes de revigorarem no meio acadêmico brasileiro o interêsse pela ciência de Savigny, Mommsen e Ferrini. Chego dêste modo, à por assim dizer profissão de fé.

"O professor de direito deve ser, junto com o magistrado e o político, o guardião da Lei e da Justiça. Quer ensinando quer pleiteando cumpre ao jurista preservar intangiveis os supremos princípios da vida moral dando ao homem seu signo distintivo de animal racional, destinado pela Providência Divina a fim superior e único. Por conseguinte acima dos interêsses contingentes e variáveis de cada momento há-de o jurista digno de tal nome respeitar e cultuar os valores permanentes e invariáveis consubstanciados nas leis, subordinando-lhes os interêsses subalternos.

"Da antiga Roma vem-nos o exemplo augusto de Papiniano, príncipe dos jurisconsultos, pagando estòicamente com a vida a recusa de justificar perante o Senado o assassínio de Geta perpetrado pelo irmão dêste, Caracala. "É mais fácil praticar um parricídio do que tentar justificá-lo" respondeu o jurista incorruptível ao imperador tirânico e dêste modo selou com a morte a união indissolúvel que deve existir entre o mais alto saber e o amor indefectivel da virtude.

"A humanidade contrita assistiu há poucos dias o falecimento de Churchill, herói da segunda guerra mundial. Onde reside a grandeza dêste ilustre inglês? Acima de tudo, na resistência, acredito, intransigente, extrema, indomável, do sentimento de Liberdade. Opondo-se à Tirania, no sentimento do destino superior do homem exigindo a subordinação dos apetites inferiores. 
"Semelhantes exemplos ilustram admiràvelmente a por mim chamada profissão de fé: devemos, como juristas e sêres humanos transigir sempre mesmo com sacrifício próprio quando se tratar de preservação da paz, da harmonia com o semelhante e da fraternidade; não podemos entretanto, sob pena de nos desvestirmos de nossa dignidade eminente, jamais pactuar com a prepotência, com o cinismo, com a brutalidade, com o desrespeito ostensivo e insolente à Lei, com a usurpação! Em tais ocasiões procuremos fôrças para resistir inspirando-nos nos exemplos dados pelos gigantes da história moral da humanidade, recordemo-nos de Papiniano em Roma e de Cícero, dizendo: "Legis servi sumus ut liberi esse possimus"! Repitamos mentalmente os conhecidos versos de Juvenal:

"Summum crede nefas, animam praeferre Et propter vitam vivendi perdere causas",

lembremo-nos de Churchill, em pleno bombardeio de sua terra, ou de qualquer outro Titã, enfrentando monstros; recitemos o Evangelho, preparemo-nos em suma espiritual e moralmente e cumpramos nosso dever fundamental de homens, resistindo quando necessário até à morte contra a Injustiça! Conquistaremos assim nossa liberdade e dignidade e mereceremos o título dignificante de Juristas!

“É tempo de terminar: faço-o aqui dirigindo saudação especial a meu eminente colega e amigo professor Washington de Barros Monteiro. Amplamente conhecido nos meios jurídicos do País, o Prof. Washington corresponde bem à figura moral do jurista. Magistrado íntegro e sagaz, ascendeu S. Excia. brilhantemente ao Tribunal de Justiça de S. Paulo, depois de haver com inteligência e honradez exercido a Judicatura no interior; nomeado desembargador veio pouco depois a ocupar por concurso uma das Cadeiras de Direito Civil em nossa Faculdade; ensinava já, aliás, a mesma disciplina na Faculdade Pau- 
lista de Direito, onde primeiro o conheci. Justamente estimado pelas qualidades de espírito e de coração tanto por colegas como por estudantes é o Prof. Washington autor de esplêndido curso de Direito Civil, abrangendo tôdas as partes de seu programa. A obra embora destinada ao ensino é sempre com proveito consultada também por advogados, professôres e magistrados. Reune assim S. Excia. em sua pessoa a dupla qualidade (característica, aliás, dos juristas romanos) de conhecedor do direito na teoria e na prática. Merecer eu neste momento a distinção de ser saudado e recebido por tão eminente professor só pode encher-me de alegria e orgulho. Apresento a S. Excia. meus efusivos agradecimentos, esperando poder gozar por muitos anos de sua benéfica influência.

"Dirijo também uma palavra especial de agradecimento a diversas pessoas cujo auxílio e assistência me foram de inestimável valor em momento crucial de minha carreira. Refiro-me, em São Paulo ao Dr. Júlio de Mesquita Filho, Diretor do "O Estado de São Paulo" e a seus colaboradores, dentre os quais o Dr. Flávio de Almeida Prado Galvão; aos Drs. Brenno Caramuru Teixeira e Carlos Woge, eminentes advogados; e no Rio de Janeiro ao Dr. Dario de Almeida Magalhães, também ilustre causídico. Êstes três profissionais conduziram com êxito o Mandado de Segurança declarando válido no Supremo Tribunal Federal o Concurso à Cátedra de Direito Romano no qual fui classificado por unanimidade em primeiro lugar. Compunha-se a banca examinadora dos ilustres professôres Mario Mazagão e Vicente Ráo, desta Faculdade e dos profs. Mario Neves Batista, Afonço Lages e Sílvio Moreira, respectivamente do Recife, de Belo Horizonte e de Belém do Pará.

"A todos êstes mestres o meu preito de admiração pelo saber jurídico que o País inteiro aliás, lhes reconhece: é para mim motivo de orgulho e incentivo ter merecido o sufrágio unânime de tão notảveis julgadores. 
“Desejo externar de público a minha gratidão a tôdas as pessoas aqui citadas, sem esquecer também os colegas como Sérgio Brotero Junqueira, João da Cruz, Vicente de Azevedo, Cândido Procópio Ferreira de Camargo, Severo Gomes, Ruy de Freitas Camargo, e os inúmeros amigos, dentre os quais José Maria Whitaker, Altino Arantes, Francisco de Paula Vicente de Azevedo, Desembargador Juárez Bezerra de Menezes e Zeferino Vaz. Merecem aqui especial menção; em homenagem no "Automóvel Club" quizeram todos, há algum tempo, manifestar-me sua simpatia. Devo-lhes, graças ao estímulo em mim infundido por seu prestigioso apoio, parte substancial do êxito de hoje. A todos os amigos, pois, presentes e ausentes, minha imperecível gratidão! 